\title{
POST-9/11 TRAUMATIC PARANOIA \\ AS REFLECTED IN DON DELILLO'S FALLING MAN
}

\author{
Siti Kurniati Rasad \\ e-mail: sitikurniatyrasyad@gmail.com \\ Achmad Munjid \\ Universitas Gadjah Mada \\ e-mail: achmad.munjid@gmail.com
}

\begin{abstract}
This article investigates how the trauma of 9/11 tragedy affects the lives of the characters in DeLillo's Falling Man and shows how the trauma of 9/11 portrayed in the novel reflects American collective trauma. This investigation is qualitative research utilizing memory and trauma as the theoretical framework. The discussion in this article reveals that individual experience the trauma of 9/11 tragedy differs from one person to another. While other characters go through their mourning successfully, the main character in the novel becomes a perennial mourner and is ceaselessly haunted by his traumatic memory due to constant avoidance from his trauma. His continuous externalization of his trauma causes him to focus on the external threats and becomes a paranoiac. On a societal level, American society is also perpetually mourning and is haunted by post-traumatic paranoia continuously. American exceptionalism, biased orientalist perspective about the orient, and alleged prolonged quasi war between Islam and the west have framed the collective experience of the trauma in binary opposite narrative of a good versus evil war. The collective trauma perpetuates and many policies are born out of their paranoia.
\end{abstract}

Keywords: 9/11 tragedy; memory; mourning; post-traumatic paranoia; trauma

DOI $\quad$ : https://doi.org/10.22146/rubikon.v6i2.61482

Available at https://jurnal.ugm.ac.id/rubikon/article/view/61482

This work is licensed under a Creative Commons Attribution-ShareAlike 4.0 International License

\section{INTRODUCTION}

Our trauma shapes us. It is there influencing us in making decision in our everyday lives. When people experience trauma, their meta-narrative that guide their
Article information

Received: 20 August, 2019

Revised: 3 September, 2019

Accepted: 17 September, 2019 life is shattered. When this happens, they can no longer perceive their world the way they used to do. All of a sudden, their personal worldview cannot be trusted. Yet, they still have to move on with their life because time does not stand still. However, their life will 
be way different since the meta-narrative they used to have has been shattered. Their formerly pre-existing patterns contouring their worldview will be now felt invalidated. In this case, according to Muller (2017, p. 7), human beings will have to create new metanarratives to move on in their life. Their traumatic experience will be taken into account in constructing this new guiding meta-narrative.

The 9/11 terrorist attack is one of the most traumatic experiences to the lives of Americans. It is considered both as individual trauma and collective trauma. That fateful day that occurred in 2001 has shattered Americans individually and collectively (Baelo-Allue, 2012, Introduction, para. 2). This means that the 9/11 incident not only shatters many Americans' individual psyche, and their personal worldview, but in fact, has also been a cultural trauma that becomes the trigger to many changes on American collectivity. The 9/11 attacks is a watershed in lives of every American. So influential the 9/11 tragedy is to America that Muller (2017, p. 18) contends that "America is inconceivable without $9 / 11$ ".

Being aware of how significant our trauma is in molding our personal lives and how the 9/11 attacks has brought many changes to American collectivity, I am convinced to venture on investigating how the trauma of 9/11 tragedy has changed Americans individually and collectively through the means of analytical reading of Don DeLillo's Falling Man. In this novel, DeLillo portrayed a character who directly experience the 9/11 attacks and is affected greatly by it. This novel recounts in detail the affects that the traumatic tragedy has had on each character.
Don DeLillo's Falling Man is one of the novels written as a response to the 9/11 terrorist attack. This novel was published in 2007 which is distanced about seven years away from that fateful tragedy. This novel has received various different comments from the reader either from those who consider it a successful novel, or those who are discontented with the recount of the 9/11 tragedy portrayed in a book, and harshly criticize the novel as simply a failure. Yet, this novel is undeniably one of the most popular novels and might have been the most anticipated fiction about the 9/11 tragedy that is ever written (as cited in Baelo-Allue, 2012, Introduction, para. 1).

My investigation will be concentrating on how the trauma of 9/11 affects American individually and collectively as the ensuing aftereffects of that frightening tragedy. As a historical, destructive, and painful event, this trauma must have struck fear into Americans. This is, to me personally, crucial to be highlighted since human beings are stirred and moved by fear in nature. Fear is important for us to survive life. Yet, in some cases, our responses to our own fear can also be outweighed with dangers for our own life. DeLillo's Falling Man will be a good reflection of how the traumatic attacks make Americans individually and collectively experience unimaginable threats that they never think of, let alone anticipate. DeLillo has moved from predicting the tragedy as reflected in his previous works to a work which portrays his understanding of the effects of the tragedy as portrayed in Falling Man. This novel written by Don DeLillo is a recount of a survivor's life and his surroundings responding to the trauma of 9/11 tragedy. Hence, I would like to see how this novel entitled "Falling Man" portrays 
those fears resulted from the traumatic tragedy and the effects it causes that are experienced individually and collectively by Americans.

The researcher applies descriptive qualitative method in conducting this research. According to Creswell (2009, p. 209), this kind of method enables the researcher to demonstrate a different approach to scholarly inquires compared to quantitative research methods. This method can apply different "philosophical assumptions, strategies of inquiry, and methods of data collection, analysis, and interpretations". This qualitative method is usable in analyzing data in the form of text and images. This research assigns the researcher to be the key instrument in his or her own research (Creswell, 2009, p. 211). This means the researcher herself or himself will be the one who gathers data through examining documents, observing behavior, or interviewing participants. In this research, the researcher conducts her duty to be the key instrument of this research by reading the novel entitled Falling Man closely and critically, analyzing it vis-a-vis to the topic of this research, gathering data from the book, classifying those data, drawing conclusion from the data, and presenting in the form of well-organized writing to the reader.

Interpretation and theoretical lens are also needed in qualitative research. According to Creswell (2009, p. 212), qualitative research obliges the researcher to make an interpretation of what they see, hear, and understand. This interpretation will be much influenced by the researcher's background, history, contexts and prior understanding. Therefore, the result of this research will be pretty much biased due to the researcher's subjectivity as a human being with her culture, faith, nationality, and her own lifelong experience as the backdrop of her mind in conducting this research. Being aware of her possibly biased perception, the researcher feels an ethical obligation to better equip herself with a lot of information as many as possible that are relevant to this research. Hence, the researcher tries to dig much information from many different sources that the researcher can possibly obtain. That information comes from varied sources either in printed, electronic, audio, or audiovisual format. Only then the researcher feels well-equipped and is ready to interpret the data that has been found related to the subject that the researcher discusses in this research.

As for theoretical lens, Creswell (2009, p. 211) argues that qualitative research always needs certain perspective to view their study. In this case, the researcher applies theory about mourning and melancholia, and paranoia proposed by Sigmund Freud, theory of perennial mourning and societal mourning theorized by Vamik D. Volkan, and the persistence of traumatic memory by Daniel L. Schacter. Mourning and Melancholia written by Freud discusses about how an adult undergoing their process in dealing with a loss. Volkan extends Freud's theory and comes up with a concept of perennial mourning and societal mourning. As for Daniel L. Schacter, he proposes theory of the nature of memory and classifies "seven sins of memory" which covers transience, absentmindedness, blocking, misattribution, suggestibility, bias, and persistence (Schacter, 2003, pp. 4-5).

This research utilizes some of the theories proposed by these scholars. The first 
problem which deals with individual experience of trauma undergone by each character in the novel will be answered by utilizing Freud's concept of mourning and melancholia, Volkan's concept of perennial mourning, and Schacter's theory of the persistence of memory. On the other hand, the second question which investigates American collective trauma will be explained by Volkan's concept of societal mourning.

In terms of data, this research relies primarily on the novel Falling Man by Don DeLillo. The data are in the form of words whether it is a dialog, monolog, phrase, sentence, or descriptions of events or characters which help narrating the story written in DeLillo's Falling Man. To better equip herself, the researcher also takes into account many written materials in the form of various writings either printed or electronic such as books, articles, etc. that the researcher considers relevant in the process of conducting the research.

As for the technique of data collection, Sutopo (2002, p. 87) argues that in a qualitative research, collecting data is done simultaneously with analyzing data. In this case, the researcher will collect data from the selected words, sentences, phrases, descriptions, that she finds related to the topic of her research in DeLillo's Falling Man. After collecting the data that the researcher gets from reading the novel closely and critically, the researcher will classify the data into certain categories and draws out a theme from those categories.

\section{DISCUSSION}

\section{Individual Perennial Mourning and Post- traumatic Paranoia in Falling Man}

Being exposed to such a traumatic painful event, all the characters within DeLillo's Falling Man and the Americans, on collective level, end up in paranoia in the wake of the tragedy. Americans individually and collectively seem to never come to an end in their mourning of the tragedy. Yet, there is not a hint of depression or melancholia. Rather, it displays symptoms of paranoia. Not only on individual level, is this paranoia also well reflected in the history of American as a nation which hints the broader consequences of collective experience of trauma. The first part of this passage is dealing with the question of how such a traumatic event affects individuals that they live their life in a constant paranoia. The second part is elaborating the issue of post-9/11 paranoia resulted from the trauma on collective level.

Being a perennial mourner means to be perennially haunted by the thing that have lost. This is another common consequence of a loss which is complicated by trauma apart from mourning and melancholia. Throughout the novel, Keith is portrayed as a perennial mourner due to his failure of working through his traumatic memory. According to LaCapra, working through is successful when one can accept what happened as something in the past and live a life forward oriented (2014, p. 22). Compared Lianne and Florence who are also most affected by the traumatic memory of 9/11 can move on with their life, Keith is different. His failure to work through his trauma makes him constantly act out his trauma until the end of the story. By constantly acting out, this means Keith's life 
after the tragedy is continuously haunted by the tragedy that all of his actions seem to be driven by his traumatic memory of the tragedy. Keith, which was once ambitious, workaholic, and energetic transforms to be someone who no longer has a vision in life.

DeLillo opens up his narrative in Falling Man with a portrayal of Keith coming out from the building in a complete shock (DeLillo, 2008, p. 7). For someone who has just nearly got killed in an accident, this is a normal reaction. Shock according to Volkan (2010, p. 92) is indicative of a first common reaction to a loss. The extreme shock he experienced lead to the linguistic paralysis and temporary forgetting. $\mathrm{He}$ is not just unable to recount the tragic event but also cannot remember it. Being unable to accept the reality, the one who have just experienced a painful tragedy usually displays a form of opposition which Freud (2010, p. 20) calls as "turning away from reality". This mechanism of reality denial frequently works in line with one's memory. The unbearable shock resulted from the trauma must have made Keith repress the memory of painful and atrocious tragedy he has just gone through. This temporary forgetting happening to Keith confirms what Daniel L. Schacter theorizes as "the adaptive feature of human mind" (2001, p. 6).

Keith's psychical struggle is so overwhelming that he finds himself being uncomfortable to talk to a stranger. $\mathrm{He}$ is found lying about his experience of surviving the attack in person. In times of trauma, it is understandable if Keith finds it uncomfortable if not impossible to open up to strangers. Americans have always been cautious when it comes to dealing with strangers they meet on the street. According to Karen Scott-hoy, American children have been taught to never talk to a stranger since they are still in primary school. This campaign is usually known as a stranger danger. This personal safety campaign intended for kids is intended to protect kids from abduction and sexual abuse. This campaign reflects that Americans have long been preoccupied with a fear of strangers (Scott-hoy, 2003, p. 302). Now that the tragedy of $9 / 11$ is perpetrated by a pack of strangers, this fear must have been intensified.

The traumatic event is usually incomprehensible to the survivor of traumatic tragedy at its initial phase. According to Caruth (2006, p. 6), a survivor of a violent tragedy is haunted not only by "the reality of the violent event" but also the incomprehensibility of the event. Keith is also haunted by this incomprehensibility. Being a survivor of such an unexpected atrocity, the tragedy is first hard to grasp. There is a passage reading, "He said, "I'm standing here," and then, louder, "I'm standing here" confirms this hypothesis (DeLillo, 2008, p. 24). This sentence is uttered by Keith when he was alone walking out of his apartment when he was there trying to take some of his stuff. He was talking to himself and trying to convince himself that he has survived the tragedy. The repeated phrase that he utters reflects his confusion of his barely believable survival.

Struggling to overcome the painful memory of the tragedy has made Keith resorts to self-deception. Trauma is a very overwhelming phenomenon that dealing with it immediately is unbearable. It is clear that by lying Keith is actually trying to avoid dealing with the memory of the painfully 
traumatic tragedy. Schacter claims, this is actually very common for those who are traumatized by certain overwhelming traumatic event to "attempt to avoid thinking" about that event. In fact, this forgetting is one of initial common responses to trauma (2001, p. 175).

Yet, memory seems to have a life of its own. The more it is suppressed, the more persistent it becomes. Suppressing the memory of a painful event leads to more frequent rumination on it which later becomes the source of more distressful and longlasting remembrance of the traumatic tragedy (Schacter, 2001, pp. 176-177). This explains why Keith seems to be stuck in his trauma until the end of the story. He flees from his own memory throughout the novel that he is never conscious of his trauma. Therefore, he never properly deals with his trauma. Yet, the natural persistence of memory and his surroundings which keeps reminding him of the event relentlessly makes his encounter with his own memory unavoidable. The memory grows more compelling as the time passes and causes him being stuck in it eternally.

This persistence of memory and how it affects Keith are portrayed very obvious in the novel as well. Keith keeps being haunted by the images of his friend, Rumsey who was dead in the 9/11 attack. The images that flash through Keith's mind are the image of Rumsey sitting in his chair helplessly when the plane had just attacked the building and everything around them began to fall down (DeLillo, 2008, p. 20). Rumsey was Keith's best friend who died on that day within the tower. Keith seems to be very close with him before the tragedy killed him. There is a strong possibility that losing Rumsey is a kind of loss that is resulted from a narcissistic hurt. Keith is portrayed as "a model of dependability for his male friends, all the things a friend should be, an ally and confidant, lends money, gives advice, loyal and so on" (p. 47). From the quotation that is taken from Nina's perspective, Keith's selfconception seems to rest much on his relations with his male friends. He probably understands himself as a loyal best friend that his male friends can trust and depend on. His failure to save Rumsey on that day has shattered Keith's self-schema. The fact that he failed to save his best friend's life on that day must have damaged his selfunderstanding about his self as this loyal friend. He seems to experience a disintegration in terms of personal metanarrative that leads to experience an unconscious loss which is usually longlasting. According to Freud, this kind of loss usually ends up in melancholia (2010, p. 21). Yet, in Keith's case, he does not display any symptom of self-reproach which is a distinguishing feature of melancholia. Instead of sinking in melancholia, his trauma seems to make him a perennial mourner.

The images of Rumsey that keeps haunting him also emphasize helplessness and survival guilt as the cause of the trauma that he suffers and how his trauma never really ends. An event becomes traumatic if it is accompanied with shame, guilt, and helplessness (Volkan, 2010, p. 97). He is haunted by his failure to rescue him throughout the novel. He keeps seeing the images of Rumsey sitting on a chair by the window of the building just as what he saw that day. This image comes in his dreams and through the flashes of images that can come to his mind in his waking hour. The memory about his failure in rescuing Rumsey seems to 
be frozen (DeLillo, 2008, p. 170). It is the images of his failure in saving his friend's life. Being a perennial mourner, he is, Keith is stuck in the memory of that day that his helplessness and guilty for his failure on that day haunts him until the end of the story.

An attempt to resort to forgetting in dealing with traumatic memory can result in "temporal disintegration" and more rumination on the painful event. This is very obvious in Keith's trauma as well. DeLillo metaphorically touches on this phenomenon in a passage reads; "he walked away from it and into it at the same time" (2008, p. 7). This quotation is a portrayal of Keith's feeling when he had managed to get out of the building almost unconsciously. He seems to experience what is called as "time collapse". He physically can go out of the building but psychically trapped within the building at the same time. His body managed to get out, but his psyche seems to be stuck within. As for rumination, Keith finds himself thinking a lot about things surrounding his life after the attack and his life before the attack. It is clear that the trauma has caused him to ruminate more. He was aggressive and quick-witted then. The trauma changes to be a reflexive man (p. 52).

The hand exercise that Keith does until the end of the story is another sign of his internal effort to freeze his mourning (DeLillo, 2008, pp. 32-33). This is common to happen in a perennial mourner. According to Volkan, for a perennial mourner, a simple hand gesture, photograph, or anything related to that painful event can be a linking object (2010, p. 102). The hand exercise is not merely an exercise to the damage happened to his wrist. This exercise is a cure to what happened inside him. This is emphasized many times in the book. In fact, even when his wrist has healed completely, he still continues doing the hand exercise (DeLillo, 2008, p. 80).

Another image that indicates his perennial mourning is the image of a shirt. Keith keeps seeing a shirt falling down repeatedly. This image of "a shirt coming down out of high smoke" has started haunting him shortly after he comes out alive of the tower (DeLillo, 2008, p. 7). This haunting image of a falling shirt seems to mark the beginning of Keith's trauma. Keith also recounts this when he first appeared in Lianne's house after surviving the tragedy (DeLillo, 2008, p. 66). Although Keith had mentioned about the shirt to Lianne when he arrived at her house, he does not seem to understand what shirt it was, why he would see a shirt in such a chaotic situation, and why it matters. Yet, as the story unfolds, there are more clues that DeLillo puts in the last part of the story, which explain what is with the shirt that Keith keeps retaining in his traumatized memory.

Keith also experiences what Freud (2010, p. 20) calls "cessation of interest in the outside world" in his essay. This is one of the phases that commonly happen to those who are mourning or sinking in melancholia according to Freud. This "cessation of interest in the outside" world is actually a result of "an exclusive devotion to mourning" (2010, p. 20). Being applied to Keith's case, this explains why he can have an affair with someone whom he would have never considered attractive before while conversely fail in rebuilding his relationship with Lianne.

"Cessation of interest in the outside world" resulted from the trauma of $9 / 11$ 
tragedy has changed Keith's personality as well. His trauma has made him less ambitious about the world he used to be so passionate about. In fact, the novel portrays him as a person who no longer has a clear vision of life. This is very different with the implicit portrayal of Keith before the tragedy. Before the tragedy took place, he was portrayed as someone who was aggressive, ambitious, fearless, and adventurous. Before the tragedy took place, he was a man who was very disciplined, workaholic, and loved doing dangerous things such as, hiking, skiing, and rock climbing (DeLillo, 2008, p. 12). Yet, after the 9/11 attack happened, he turns to be a man who is confused about what he will do next.

DeLillo touches upon another kind of trauma through Lianne's perspective in the wake of 9/11 tragedy. Unlike Keith who goes through the tragedy of $9 / 11$ attack directly by being a survivor in one of the cities where it happened, Lianne experiences the 9/11 indirectly. She learns the painful event of 9/11 attack from her being exposed to stories about it in television, newspaper, internet, or stories from those who witnessed it directly. The trauma experienced by Lianne is what scholars such as Ann E. Kaplan call "vicarious trauma" (Kaplan, 2005, p. 87). This kind of trauma is a trauma resulted from indirect exposure to a traumatic tragedy. This can commonly happen to the relatives of those who are victimized by certain catastrophe, clinicians who hear the recount of certain traumatic tragedy, or those who live nearby where the catastrophe happens (as cited in Erwin, 2002, p. 2).

If Keith runs away from the story that has traumatized him, Lianne is portrayed full of curiosity about the tragedy. Lianne is traumatized by indirect exposure to the story of 9/11 tragedy to an extreme degree that she cannot sleep well at night. In one passage, she said, "I wake up at some point every night. Mind running nonstop. Can't stop it. Thoughts I can't identify, thoughts I can't claim as mine" (DeLillo, 2008 p. 94).

Being someone who has been traumatized in the past by her father's suicide, it is not surprising to find Lianne is vulnerable to vicarious trauma. Unlike Keith who is only traumatized by the 9/11 tragedy, Lianne is portrayed having double trauma. Her trauma of her father's suicide which took place prior to $9 / 11$ tragedy merges with her vicarious trauma of $9 / 11$ tragedy. Unlike Keith who is unconscious about his trauma, Lianne is very aware of hers. Not only aware of its existence, she also knows its origins. This is actually very common for those who suffer vicarious trauma since their trauma roots in their process of understanding a painful event in the first place (as cited in Kaplan, 2005, p. 89). Her awareness of trauma enables her to deal with it in a more proper context. Unlike Keith who seems to avoid with his internal struggle with trauma, Lianne is struggling to ease her trauma by telling it to a pack of Alzheimer patients that she holds a meeting with (DeLillo, 2008 p. 96).

Florence is another character in the novel who suffers trauma from 9/11 tragedy. She is one of the victims of the attacks that happened on that fateful day but managed to get out alive. Florence and Keith shared the same traumatic tragedy. However, unlike Keith, Florence is portrayed as a character that does not experience some kind of "linguistic paralysis", or "temporal disintegration". She seems to suffer less 
compared to Keith who is also another survivor from the same traumatic tragedy. Both Florence and Lianne's experience with trauma are made ease by retelling the tragedy to others and their belief in religion.

Another character which also experiences trauma vicariously is Marthin, Nina's lover. His trauma is portrayed in one passage where he starts to see the towers in a still life painting (DeLillo, 2008, p. 39). This is very normal for him to develop trauma symptoms as well since he has people in the states he has known well for long. His trauma must be induced by empathy to Americans especially to Keith, Lianne, Justin, and Nina, his lover. Yet, he holds opinions which are close to those typically expressed by European scholars in observing the tragedy. Nina's experience of the trauma of $9 / 11$ on the other hand confirms the link which connects emotion and memory. Being a character who suffers Alzheimer, Nina surprisingly remembers a lot from her past. Confronted by Martin's opinion that put the blames on America and the force of the situation in the wake of the tragedy, Nina can recall how he met Martin and his mysterious past (DeLillo, 2008, p. 108).

The trauma of 9/11 tragedy has been crucial to understand the behavior of each character in Falling Man. Despite its ostensible randomness that is reflected in the way they live their life after the tragedy, it is relatively easy to point out the significance of the tragedy to their life. The tragedy has made them paranoiacs. There are several indicators of this post-9/11 paranoia which are portrayed in Falling Man. Those are the constant fear of another attack, their delusional fantasy about the attack, the constant suspicion and hostility to strangers, the clinging to familiarity, exclusivity, and self-absorption.

Every day after the 9/11 attacks, Keith is haunted by anxiety, and extreme fear. This has been well portrayed within the novel by beginning it from Keith's perspective where he found the world around him to be "a world, a time, and space of falling ash" (DeLillo, 2008, p. 7). This is not a mere description of his surroundings. This is also a metaphor to the frozen picture of the tragedy which has preoccupied his mind shortly after surviving the tragedy. It seems that Keith is feeling threatened by the neighborhood he has actually been familiar with. What was once familiar for Keith has changed. A street, and everything that he has walked through must have been familiar for him since it is near the place where he worked. Yet, he finds it strange and unfamiliar. These changes also are also felt by Lianne who are also traumatized by the tragedy through her indirect exposure to it. Indirect exposure to 9/11 tragedy through different means has traumatized her to the extent that she no longer finds the city where she lives most of her lifetime the same (p. 28). The way Keith and Lianne react to this elusive change emphasize what is hidden behind their changing perception of their surroundings. Both characters experience a sudden loss of safety and stability due to a sudden disturbance on their surroundings. According to Halbwachs (as cited in Whitehead, 2010, p. 137), "the space of the city provides a sense of stability for the urban groups". This means, a sudden change to a landscape of New York city must have presented both Lianne and Keith a sudden loss of stability. This constant anxiety has significantly affected Keith that he decides that he can no longer live in his apartment and must go back to live with 
Lianne. Keith seems to be preoccupied by his anticipation of another possible attack. In fact, this can be spotted by looking at his action of counting of the One Liberty Plaza building that is overlooked from his apartment. As it reads, "he looked at the visible sliver of One Liberty Plaza and began to count the floors, losing interest about halfway up, thinking of something else" (DeLillo, 2008, p. 23). His anticipation of being trapped in the same tragedy can be found as well in his preference to climb nine flights of stairs get to his apartment rather than taking the elevator (p. 23). As for Lianne, this paranoia is easier to spot. Her paranoia resulted from the trauma of 9/11 attacks is so intense that she made a big deal about her child and his friends searching the sky for another plane (p. 114). Another obvious symptom of paranoia resulted from the 9/11 tragedy on Lianne is the fear of taking subway. Since the 9/11 tragedy happened, Lianne no longer dare to take subway. Instead of taking subway, she prefers to walk (p. 124). The repressed feeling of being constantly endangered provides an explanation as to why Keith prefers to go back to his estranged wife after the tragedy. Clinging to family for safety seems to be the same reason why Lianne generously accepts Keith back. Seeking safety in a family is actually a very reasonable choice among Americans considering that they have gone through such an atrocious tragedy. Given that the terrorists who perpetrated the attacks were reported living among Americans before undertaking their mission, this surely brings an impression that they could be present anywhere and anytime (Jackson, 2009, p. 27). This means, people will constantly worry about the possible coming of another deadly attack because terrorists might live with them in disguise.

Lianne's tendency to isolate herself from people confirms this hypothesis as well. Lianne tends to isolate from people ever since she is traumatized by the attacks. It is implied Lianne intentionally isolate herself from her friends circle after the 9/11 tragedy took place. On the other hand, the tendency to prefer solitude and shut people out resulted from paranoia comes later in Keith's case. Although, in the beginning of the novel, he has been portrayed preferring solitude, it seems that the real reason behind his preference is his "excessive devotion" to mourning. He seems to be resistant to fear in the first part of the novel due to a problem with his amygdala. He does not show a hint of fear in responding to a situation where he is supposed to do. However, as he gets more information about the tragedy as the story flows, his problem with amygdala seems to heal gradually. As Schacter asserts (2001, p. 181) that amygdala can be reactivated during "fear conditioning", Keith's seems to show a symptom of paranoia as his memory about the tragedy is provoked by information that he gets from news and everything around him which reminds him of the tragedy.

This brings us to another hypothesis which signals the overwhelming paranoia experienced by the characters within the novel. Since the attack can happen everywhere anytime, this puts everyone in a constant suspicion with each other. Keith is also portrayed being constantly cautious when he is among strangers (DeLillo, 2008, p. 145). This constant suspicion affects his relationship with one of his friends that he actually has known for years. After the tragedy, Keith feels no need to rebuild their 
friendship that they used to have. Terry Cheng which might look un-American for Keith seems to be the reason why Keith behaves this way. Terry Cheng is a Chinese guy who is probably foreign enough to be the possible suspect of another terrorist attack ( $\mathrm{p}$. 167).

Terry Cheng is not the only one who is suddenly unwelcomed in America as portrayed in the novel. Being a lover for Nina for 20 years does not prevent Marthin from being considered as a probable enemy for Nina, and let alone Lianne, Nina's daughter. Suddenly, Martin becomes a stranger with enigmatic past for Nina, his own lover, and Lianne whom he has known for years (DeLillo, 2008, p. 110). Lianne's paranoia is portrayed in a very obvious way in several conversations. She is very upset to find out that Martin's identity is never clear although this is actually not a brand-new information. Nina's story about Martin's past above shows how Nina no longer believes in Martin. Martin is now a possible threat for her. This is understandable since Martin is practically not an American. He is portrayed as an art dealer from Europe. This means he could be one of those threats that might destroy America.

Her hostility towards Islam and Muslims can easily be spotted by how disturbed she is when she heard some foreign music from her neighbors across the hall. Hearing music which she assumes belonging to Islamic tradition, she is thinking of "knocking" her neighbor's door to tell her to stop playing her music (DeLillo, 2008, p. 53). Her neighbor is actually a Greek woman, yet the music does not sound like something from Greek in Lianne's ears. She jumps into conclusion that this foreign song must come from Islamic tradition. In the end she decided to go to her neighbors and hit her on face because her neighbors insist on keeping her music on (p. 89). What Lianne has done to her neighbors is a reflection of how Americans perceive Islam after the $9 / 11$.

Although all characters seem to be paranoid all the time in the wake of the tragedy, Keith will be the only one who suffers longer from it. Since paranoia is actually a defense mechanism to avoid the internal struggle with trauma that one will focus on the outside threat, as asserts Freud (as cited in Erwin, 2002, p. 409), Keith will still be paranoid for quite a long time in the future. He seems to still escape his own internal struggle with trauma until the end of the story. Although he remembers the whole tragedy in the last part of the story, his constant externalization through the hand exercise reflects his continuous struggle to avoid the "internal deficiency". Paranoia is a symptom resulting from avoidance to deal with internal wound. As long as the psyche is not taken into account in the process of healing, paranoia will always be present embedded in the process of mourning the tragedy.

\section{Attack on America as a Whole and American Paranoia}

On societal level, perennial mourning is also still happening to American society. Being constantly paranoid about terrorism is a proof that America as a whole has never completed its mourning process and is stuck eternally on the traumatic memory on that day. Being eternally haunted by the trauma of 9/11 makes America seems to lose its exceptional characteristic as a nation. Several policies that were born in the wake of 9/11 tragedy are still prevailing. Other policies are 
born quite recently driven by the trauma of the tragedy that took place years away in the past. The trauma of 9/11 attacks has caused America as a whole to be paranoid eternally. The tragedy not only results in the collapse of several buildings in America, the nation as a whole is also falling down.

The 9/11 tragedy must have been collectively traumatic for Americans in general. A sudden change in several landscapes of America affected by the attacks must have been troubling for American society. As a social group, the physical changes happened to their neighborhood must have been the source for American society to "retrieve" their memory of the tragedy. This nature of collective memory is addressed by Halbwachs when he states that "collective memory necessarily unfolds within a spatial framework" (as cited in Whitehead, p. 137). Unexpectedness as one of the things which often complicates a mourning process is inherent in the tragedy of 9/11 attacks. Being swayed by a self-understood exceptionalism for such a long time certainly makes the event harder to grasp at first and leaves Americans in awe and shock. American society for the first time in history feels a sudden loss of safety. In the wake of the $9 / 11$ attacks, America as a nation deals with the shattered assumptions which has long been the source of cohesion to unite the nation together and from which policy to manage society are born. Shame and humiliation are embedded in the tragedy of $9 / 11$ as well. For a nation that believes itself to have the strongest, unbeatable power, the $9 / 11$ attacks must have wounded the pride of America as a nation. Kaplan (2005, p. 16) emphasizes this wounded pride as well by saying that the brilliance of the terrorist in undertaking the attacks makes the event more difficult to grasp for Americans.

Dealing with the unexpected loss of stability, the loss of safety, helplessness, shame, and humiliation resulted from the attack, the 9/11 attacks must have been very traumatic for America. Since the calamity is man-made, it is normal for America to be preoccupied with fear of another attack. Fear is essential in human life since it helps to survive life. Yet, a fear which transforms into a paranoia can be dangerous. Hence, it is important to mourn and then move on.

America as a nation also resorts to three common symptoms proposed by Volkan as indicative of societal mourning (2010, p. 105). Those symptoms are quite similar to those of individual mourner. The society that mourns will feel the urgent need to externalize their shared feeling by building monument or other memorial sites, suffers "chosen trauma", and the eventual emergence of "political entitlement ideology". The symptoms are still relevant in America nowadays. Their relevance confirms the hypothesis that Americans are a society with perennial mourning.

The establishment of memorial sites which is one of the symptoms of societal mourning does exist in the way America as nation dealing with the 9/11 traumatic tragedy America as well. Ground Zero memorial and museum are now solemnly standing at the site where the twin towers used to stand. Besides, there is an annual remembrance of this tragedy shared by every American and a huge number of others memorial sites in many different places in America. Although the memorial sites have been established, the mourning of the 9/11 tragedy seems 
incomplete. In fact, the reactivation of the memory that is done annually seems to freshen up the painful trauma every year. The mourning never ends.

What seems to perpetuate the trauma of 9/11 attacks is the construction of narrative done by the authority as a war of good vs. evil. According to Alexander (2012, p. 3), when it comes to a trauma that is shared collectively, narrative is so crucial. Since American exceptionalism is basically the binary opposite narrative of good us versus evil others, the traumatic tragedy which is perpetrated by others fits perfectly well in it. This is also addressed by William V. Spanos by describing America as a nation with a selfscheme of exceptionalism embedded with "a perpetual need for frontier or enemy". The 9/11 tragedy qualifies for that "liminal moment of American history" which imposes the double standard inherent in American exceptionalism (William, 2013, p. 296). The tragedy of 9/11 attacks draws a clear dividing line between America and Muslim as the other side. Since American Exceptionalism is a notion where many policies are drawn from, this necessarily means, the $9 / 11$ tragedy will remain potent to be a source of justifications for any policy to come.

This good vs evil narrative which is inherent in American exceptionalism mixed with biased orientalist perspective about the orient makes people forget to question the necessity of the war on terror, and all other policies which actually violate their civil liberties and brings disadvantages. Most people seem to be convinced that it is normal for America to go to that length for the sake of nation's security. This good vs. evil narrative provides a justification for many crimes perpetrated for the sake of defense.
The trauma which is incorporated into American exceptionalism is worsened by the long history of conflict between Islam and the west. One of the embodiments of paranoia is war on terror. This war with all its controversies is a result of the prolonged "quasi war" between the west and Islam and the trauma of 9/11. This paranoia is also shared collectively that it becomes such a glue to unite American society. Collective memory of the tragedy that is preserved by the 9/11 memorial sites and annual commemoration seems to present a common enemy which somehow binds the nation together.

Americans have witnessed a growing patriotism in their nation in the wake of the tragedy. This is also felt and portrayed by Kaplan in her book discussing the remains of 9/11 tragedy. This is reflected in the many sentiments written everywhere following the tragedy. The sentences such as "we love America", "United We Stand: God Bless America", "The terrorist thought that they can tear us apart. But it brought us together", "We are Not Broken" are all the rage written around memorial sites and all over the nation (2005, p. 9).

The shared memory of the traumatic tragedy of 9/11 has now become such a large identity marker for America embedded in their belief in exceptionalism that dark side which is the opposite of the cohesive element of the tragedy is suddenly salient as well. This dark side is the exclusivity which is now inherent in the concept of American exceptionalism. American exclusivity after the tragedy of 9/11 attacks also confirm its perpetual paranoia. It is clear that Trump's policy is driven by paranoia of another attack. Trump's immigration policy which prohibits 
Muslims from entering the states is just one of these counter-terrorism policies which marks this exclusivity. According to Gilsinan (2018, para. 8), Trump has explicitly stated that terrorist attacks can happen to America since America accept them to live in America.

The enemy within narrative and the consequences it brings about are another embodiment of what Freud (as cited in Erwin, 2002, p. 410) enlists attributes of paranoia. As Freud asserts that paranoia makes people who suffers from it "anticipates and perceives an attack" even when there is not any hint of threat. The enemy within narrative and its manifestations are a realization of this symptom. Feeling constantly threatened by an attack which nobody could predict make Americans anticipate it almost in any way possible. This explains why counter-terrorism measures are flourishing in the wake of the 9/11 attacks.

Suspicions to anyone resulted from posttraumatic which is experienced individually as represented in the characters portrayed in The Falling Man also happens collectively. The flourishing conspiracy theory is just another symptom of paranoia resulted from the 9/11 tragedy. The shared feeling of guilt and helplessness accompanied by people's distrust on the government lead people to believe that their own government is probably the actors behind this atrocious tragedy. Being overwhelmed by a constant fear of another attack while doubting the ability of the government in protecting the nation make many people resort to believe in the conspiracy theory even when there have been a lot of efforts trying to debunk the myth of conspiracy theory.
Islamophobia is another manifestation of paranoia shared by American society. Haunted by the painful memory of 9/11 attacks which is perpetrated by Muslim and the prolonged ingrained biased orientalist perspective have made life terrible for American Muslims. According to DesmondHarris (2016, para. 14), there are 12 murders, 29 physical assaults 50 threats against persons or institutions, 54 acts of vandalism or destruction of property, eight acts of arson, and nine shootings or bombings victimizing American Muslims or those that look like Muslims.

Muslims or middle eastern looking people are not the only community who suffer from the backlash of $9 / 11$ attacks. LGBT and queer people are another community which is affected by the posttraumatic paranoia in the wake of the tragedy. Phillip Henry (2018, para. 9), an LGBTQ advocate on the other hand, highlights that LGBT and queer people is a community which people usually point a finger at when it comes to a catastrophe that is beyond human control. Ever since the tragedy hits America, America has called out for unity which excluded several people, including LGBT and queer people. In an online article retrieved from https://www.intomore.com/impact/howlgbtq-people-were-blamed-for-9-11, he claims that ever since the attacks hit America, America as a nation shows itself more as a white Christian nation. This means, Americanness is defined by people's compatibility with Christian values. Obviously, the LGBT and queer people are one of the communities which are excluded from this definition.

An effort to democratize other nations that are claimed explicitly or implicitly 
support terrorism is a result of paranoia resulted from the 9/11 attacks. In order to prevent another attack to happen, it is not enough to enough for America to practice a lot of counter-terrorism measure within the country. They consider it necessary to impose their democratic ideals as the merit of their superior culture upon the Islamic nations. Considering that America has always considered itself as being superior compared to any other nation, it makes sense if it will resort to this kind of thinking. To fight the fight against terrorism, it is necessary to make other nation to think and behave like America. This is also addressed by Stewart (2009, p. 11) who states that the final strategy to defeat terrorism is to make Afghanistan more democratic like America.

All those paranoid responses in dealing with the trauma of $9 / 11$ tragedy is indeed what is called political entitlement ideology that is conceived by Volkan. It takes a different form in the 9/11 tragedy. While Volkan's theory discusses about taking back all the lands which was once owned by the traumatized group through the means of reactivation of a historical trauma (2010, p. 108), it does not happen in the way America responds to the 9/11 tragedy. Since what is lost is security and wounded national pride, there have been a lot of endeavors embodied in many controversial policies resting on the logic of countering the horror of terrorism, guaranteeing the security, preventing other terrorist attacks to happen, or returning and claiming back America's position as a leading nation. The memory of 9/11 tragedy is indeed invoked to return the feeling of safety and American national pride to post-traumatic American society.
The desperate need to return American national pride in the wake of $9 / 11$ tragedy is addressed also by Chomsky in his book Pirates and Emperors Old and New International Terrorism in the Real World. Quoting Winston Churchill's statement before WWI saying that American wealth and possession that have been possessed should be maintained through violence (2015, p. 18), he asserts that America has always been a nation who proves its superiority through the means of violence (2015, p. 188). Framed by the collective traumatic memory of $9 / 11$ tragedy and its self-understood exceptionalism, America as a nation feels entitled to act on its own in bringing justice to its society and defending the whole world by invading Afghanistan and Iraq that are claimed as the haven of terrorist organization. This invasion and other atrocities ensuing it remain almost unchallenged since it is supported by the traumatic experience of the 9/11 tragedy suffered by American citizens.

\section{CONCLUSION}

Don DeLillo's Falling Man is a novel which reflects individual and collective experience in dealing with the trauma of 9/11 tragedy. The title Falling Man that is chosen by DeLillo seems to resonate with what Keith experiences as portrayed by the novel and American society as a whole. The trauma of 9/11 has changed Keith who was once ambitious, quick-witted, and workaholic to be a person who no longer has a vision in life. He seems to be constantly haunted by the images of that day that he fails to move on and living his life in the way he used to be. This can be parallelized with the condition of American society who also seems to worsen gradually due to societal perennial mourning and post-9/11 traumatic paranoia. American 
society feels constantly threatened by terrorist attack by unknown strangers. Being haunted by the traumatic memory of the tragedy makes America resorts to counter-terrorism policy which is costly and controversial. Besides losing a lot of money in the policy, the way America respond to the tragedy has made it lose its reputation as a country that embrace democratic values. Many other nations condemn America for what it does. American exceptionalism is starting to lose its relevance as America as a nation starting to lose its prolonged good reputation.

\section{REFERENCES}

Alexander, J. C. (2012). Trauma: A Social Theory. Cambridge: Polity Press.

Baelo-Allué, S. (2012). 911 And the Psychic Trauma Novel Don DeLillo's 'Falling Man' El 11 De Septiembre y La Novela De Trauma Psicológico 'Falling Man', De Don DeLillo. Atlantis, 4(1), 63-79. Retrieved February 4, 2019, from http://www.jstor.org/stable/43486021

Caruth, C. (2006). Unclaimed Experience: Trauma, Narrative, and History. Baltimore: The Johns Hopkins University Press.

Chomsky, N. (2015). Pirates and Emperors, Old and New: International Terrorism in the Real World. Chicago, IL: Haymarket Books.

Creswell, J. W. (2009). Research Design: Qualitative, Quantitative, and Mixed Methods Approaches. Thousand Oaks, CA: SAGE Publications.

DeLillo, D. (2008). Falling Man: A Novel. New York: Scribner.

Desmond-Harris, J. (2016, September 09). The Way We Talk about Islamophobia
Every 9/11 Anniversary is Maddeningly Oversimplified. Retrieved May 5, 2019 , from

http://www.vox.com/2016/9/9/1285691

2/islamophobia-september-11-

oversimplified

Erwin, E. (2002). The Freud Encyclopedia: Theory, Therapy, and Culture. New York: Routledge.

Freud, S. (2010). Mourning and Melancholia (L. G. Fiorini, T. Bokanowski, \& S. Lewkowicz, Eds.). In On Freud's Mourning and Melancholia, 19-34. London: Karnac Books.

Gilsinan, K. (2018, December 11). Trump Keeps Invoking Terrorism to Get His Border Wall. Retrieved June 6, 2019, from

http://www.theatlantic.com/internationa 1/archive/2018/12/trump-incorrectlylinks-immigration-terrorism/576358/

Henry, P. (n.d.). How LGBTQ People Were Blamed For 9/11. Retrieved May 24, 2019,

from http://www.intomore.com/impact/howlgbtq-people-were-blamed-for-9-11

Jackson, R. (2009). The 9/11 Attacks and The Social Construction of a National Narrative (M. J. Matthew, Ed.). In R. Stewart (Ed.), The Impact of 9/11 on The Media, Arts, and Entertainment, 25-35. New York: Palgrave Macmillan.

Kaplan, E. A. (2005). Trauma Culture the Politics of Terror and Loss in Media and Literature. Piscataway: Rutgers University Press.

LaCapra, D. (2014). Writing History, Writing Trauma. Baltimore, MD: Johns Hopkins University Press. 
Muller, C. (2017). September 11, 2001 as a Cultural Trauma: A Case Study through Popular Culture. Cham, Switzerland: Palgrave Macmillan.

Schacter, D. L. (2003). The Seven Sins of Memory: How the Mind Forgets and Remembers. New York: Houghton Mifflin Company.

Scott-hoy, K. (2003). What Kind of Mother ...? An Ethnographic Short Story (N. K. Denzin\& Y. S. Lincoln, Eds.). In 9/11 in American Culture, 297-304. New York: AltaMira Press.

Stewart, R. (2009). Foreword (M. J. Morgan \& R. Stewart, Eds.). In The Impact of 9/11 on The Media, Arts, and Entertainment, Ix-Xiv. New York: Palgrave Macmillan.

Sutopo, H. B. (2002). Metodologi Penelitian Kualitatif Dasar Teori dan Terapannya Dalam Penelitian. Surakarta: Sebelas Maret University Press.

Volkan, V. D. (2010). Not Letting Go: From Individual Perennial Mourners to Societies with Entitlement Ideology (L. G. Fiorini, T. Bokanowski, \& S. Lewkowicz, Eds.). In On Freud's Mourning and Melancholia, 90-109. London: Karnac Books.

Whitehead, A. (2010). Memory. London: Routledge.

William, S. V. (2013). American Exceptionalism in the Post-911 Era. Symploke, 21(1-2), 291-324. Retrieved May 3, 2019, from https://www.jstor.org/stable/10.5250/sy mploke.21.1-2.0291 